Article

\title{
Leveraging the Advantages of Additive Manufacturing to Produce Advanced Hybrid Composite Structures for Marine Energy Systems
}

\author{
Paul Murdy ${ }^{1, * \mathbb{C}}$, Jack Dolson ${ }^{1}$, David Miller ${ }^{2}$, Scott Hughes ${ }^{1}$ and Ryan Beach ${ }^{1}$ \\ 1 National Renewable Energy Laboratory, Golden, CO 80401, USA; jack.dolson@nrel.gov (J.D.); \\ scott.hughes@nrel.gov (S.H.); ryan.beach@nrel.gov (R.B.) \\ 2 Department of Mechanical and Industrial Engineering, Montana State University, Bozeman, MT 59715, USA; \\ davidmiller@montana.edu \\ * Correspondence: paul.murdy@nrel.gov; Tel.: +1-303-275-4982
}

check for updates

Citation: Murdy, P.; Dolson, J.; Miller, D.; Hughes, S.; Beach, R. Leveraging the Advantages of Additive Manufacturing to Produce Advanced Hybrid Composite Structures for Marine Energy Systems. Appl. Sci. 2021, 11, 1336. https://doi.org/ 10.3390/app11031336

Academic Editor: Marco Mandolini

Received: 4 January 2021

Accepted: 29 January 2021

Published: 2 February 2021

Publisher's Note: MDPI stays neutral with regard to jurisdictional claims in published maps and institutional affiliations.

Copyright: (c) 2021 by the authors. Licensee MDPI, Basel, Switzerland. This article is an open access article distributed under the terms and conditions of the Creative Commons Attribution (CC BY) license (https:/ / creativecommons.org/licenses/by/ $4.0 /)$.
Featured Application: This work outlines the opportunities for producing novel hybrid structures for marine energy systems by leveraging the benefits of combining additive and composite manufacturing techniques, and the potential this has for rapid prototyping.

\begin{abstract}
Many marine energy systems designers and developers are beginning to implement composite materials into the load-bearing structures of their devices, but traditional mold-making costs for composite prototyping are disproportionately high and lead times can be long. Furthermore, established molding techniques for marine energy structures generally require many manufacturing steps, such as secondary bonding and tooling. This research explores the possibilities of additively manufactured internal composite molds and how they can be used to reduce costs and lead times through novel design features and processes for marine energy composite structures. In this approach, not only can the composite mold be additively manufactured but it can also serve as part of the final load-bearing structure. We developed a conceptual design and implemented it to produce a reduced-scale additive/composite tidal turbine blade section to fully demonstrate the manufacturing possibilities. The manufacturing was successful and identified several critical features that could expedite the tidal turbine blade manufacturing process, such as single-piece construction, an integrated shear web, and embedded root fasteners. The hands-on manufacturing also helped identify key areas for continued research to allow for efficient, durable, and low-cost additive/composite-manufactured structures for future marine energy systems.
\end{abstract}

Keywords: marine energy; tidal turbine; design for additive manufacturing; composite manufacturing; hybrid structures; composite structures

\section{Introduction}

Marine energy systems can take many forms, such as tidal/ocean current turbines, crossflow turbines, wave point absorbers, and oscillating surge flaps and water columns [1] Because of the nascent nature of the industry, system designers and developers are yet to converge on a single design philosophy and may never do so because of the broad variety of potential operating conditions (see Figure 1). Many marine energy developers are still very much in the prototyping phases of their designs and system deployments. As a result, there is a great opportunity for low-cost, short-lead-time prototype manufacturing techniques to expedite the deployment of devices for testing and validation. 

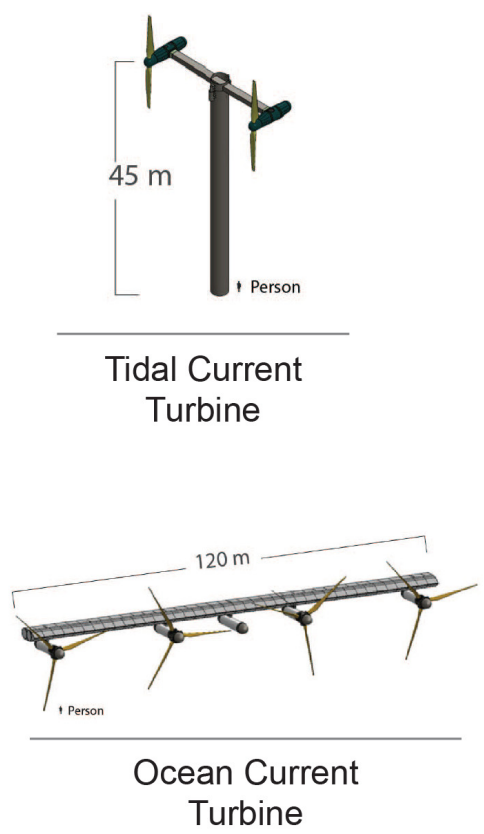

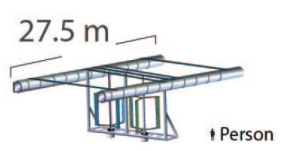

River Current Turbine

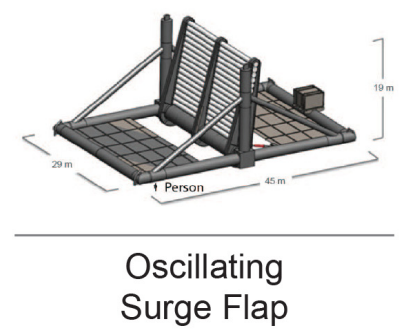

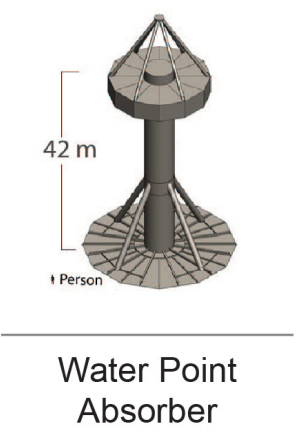

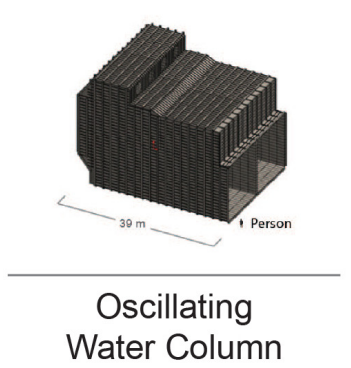

Figure 1. All six reference models developed by the Department of Energy Reference Model project [1]. Graphics courtesy of Sandia National Laboratories.

Composite materials, such as fiberglass/epoxy, are an attractive material choice for marine energy systems because of their low cost, high stiffness and strength, and resistance to environmental degradation [2]. Material density and structural mass are of lower importance because the structures are submerged underwater where buoyancy forces offset gravity-induced forces. In fact, marine energy structures are often filled with ballast such as concrete, epoxy slurry, or water to minimize buoyancy loads [3]. Naturally, a large amount of design and manufacturing knowledge has been taken from similar industries, such as wind blade manufacturing and composite boat building. Tidal turbine blades in particular are very similar in design to wind turbine blades, but on a smaller scale and with different loading and stiffness requirements [3]. They also rely on very similar manufacturing techniques and processes; for example, vacuum-assisted resin infusion molding (VARIM) of multiple shells and webs that are subsequently bonded together. The mold making for this process is incredibly expensive and time-consuming [4]. Depending on blade length, molds can cost in the order of hundreds of thousands to millions of dollars, with lead times in excess of 6 months [4], although very little public information is available in this area. This is acceptable on a mass-manufacturing scale in which hundreds of components will be produced from the same set of molds but may be unattainable for small-scale developers in the prototype testing phases of their development, particularly if designs are continuing to evolve. Despite this, large-scale mold manufacturing processes have changed very little in the last 20 years, highlighting a need for faster and cheaper molding practices for large-scale composite structure prototyping and development.

A variety of additive manufacturing processes have the potential to fill these gaps in the marine energy system structural design and validation process. In particular, recent advances in large-scale fused deposition modeling (FDM) have shown exceptional promise for reducing costs and lead times for wind turbine blade molds and components [5-7]. This is particularly exciting for exploring on-site manufacturing and prototyping unique test deployment concepts [8,9]. Another area of interest in FDM style printing is the coextrusion of continuous fiber polymer composites [10], allowing for the direct printing of fiber-reinforced polymers with no molding required at all. This technology is still relatively new and only available at a small scale, with low-fiber-volume contents $(<35 \%)$ [11] and a high probability of manufacturing defects like poor consolidation, but may provide an alternative to traditional composite manufacturing processes in the future. 
Based on these current advances in additive manufacturing and industry needs, this research hypothesizes that they will allow for novel innovations in marine energy system composite structure prototyping and manufacturing. Instead of using additive manufacturing to produce external/female composite molds, we propose that internal/male composite molds can be additively manufactured and be a permanent part of the final structure, resulting in low-cost, short-lead-time hybrid structures. This approach would allow for novel manufacturing and structural features previously not possible with traditional composite manufacturing techniques. This article serves as a starting point to explore this unique manufacturing approach by identifying several key features and process steps that can be coalesced for potentially more efficient manufacturing and more reliable composite structures. We demonstrated the innovations via a conceptual design and manufacturing of a reduced-scale tidal turbine blade section, which enabled us to identify key features that were particularly beneficial to the manufacturing process and blade structural design. It also allowed us to pinpoint critical areas for future research into the additive/composite hybrid manufacturing process. In this research, the conceptual design was solely a design to demonstrate the manufacturing process, rather than complete holistic approach including the structural and hydrodynamic design. Future research will concentrate on the full structural design to allow for comprehensive structural, techno-economic and process time analyses.

\section{Design Methods}

To show the true potential for using additive manufacturing to produce internal composite molds for tidal turbine blades, we evaluated traditional mold and blade manufacturing practices to identify key process steps and features for innovation. We then used the analysis to develop a conceptual design of a hybrid composite/additively manufactured tidal turbine blade with novel integrated features.

\subsection{Key Features}

Figure 2 shows the general process steps for manufacturing a traditional tidal turbine blade mold set. The mold set generally consists of two halves: one for the low-pressure side of the turbine blade and one for the high-pressure side of the blade. First, a master plug is machined from structural foam, which is then sanded, finished, and prepared to create a splash mold from the low-pressure side of the blade plug. For the splash mold, fiberglass/epoxy or a material similar to the final blade is typically laid over the plug, cured, and removed from the plug. The same is repeated for the high-pressure side. Support structures are then built around the splash molds and their surfaces are sanded and prepared for composite manufacturing. Overall, the mold manufacturing process is slow, expensive, and labor-intensive. Figure 2 also shows how additive manufacturing can significantly simplify this process. In addition, using a permanent internal mold means that only one mold is required instead of two halves. After printing, molds typically require a moderate amount of machining and sanding to smooth the filament lines, which sometimes can be integrated into the printing process $[5,7,12]$. Finally, the molds are typically sealed to promote vacuum integrity for typical composite manufacturing techniques. Post et al. have demonstrated these techniques at a large scale for female molds and shown that large-scale additive manufacturing processes can significantly reduce the costs and lead times of large composite molds $[5,7]$. The disadvantage of using an internal mold as a permanent part of a hybrid structure is that one must be printed and prepared for every component to be manufactured, whereas a pair of high-quality traditional female molds can be used to produce hundreds of components, but structural or hydrodynamic design iterations cannot be implemented. 


\section{Traditional Mold Manufacturing}

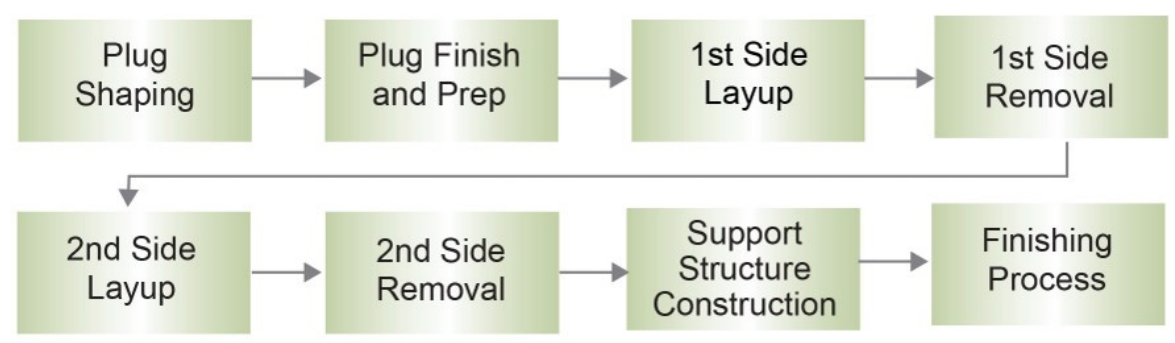

\section{Additive Mold Manufacturing}

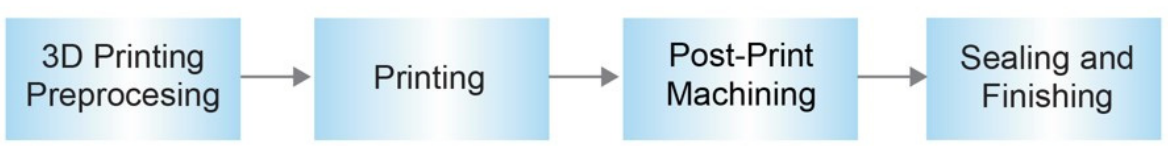

Figure 2. A comparison of the general process steps required to produce a traditionally manufactured composite mold vs. an additively manufactured composite mold.

Manufacturing composite tidal turbine blades typically requires several significant process steps (see Figure 3). Blades are made in multiple components: a high-pressure skin, a low-pressure skin, and a shear web or box spar depending on the length of the blade $[4,13,14]$. These components are often manufactured from fiber-reinforced composite and composite sandwich structures. The components are bonded together using structural adhesives. Several postprocessing steps are also required, such as trimming excess composite from the two bonded skins, and sanding and grinding the outer surfaces to their final hydrodynamic shapes. The root end of the blade must also be prepared for connection to the hub of the tidal turbine, typically in the form of a bolted connection. Bolted connections in composite laminates and composite/metal interfaces can be particularly problematic [15], and a variety of different designs exist in this area. The composite layup in the root section is built particularly thick, so that lengthwise holes can be included or drilled through the laminate and threaded sleeves can be bonded or secured inside. This can be a particularly time-consuming and expensive manufacturing step, as a result of expensive preforms, adhesives, and specialized equipment.

\section{Traditional Composite Structure Manufacturing}

\begin{tabular}{|c|c|c|}
\hline Preprocessing & Processing & Postprocessing \\
\hline $\begin{array}{l}\text { - Mold prep } \\
\text { - Material cutting } \\
\text { - Preform creation }\end{array}$ & $\begin{array}{l}\text { - Structural component } \\
\text { manufacturing } \\
\text { - Multiple skin layups } \\
\text { - Adhesive Bonding } \\
\text { - Demold }\end{array}$ & $\begin{array}{l}\text { - Trim } \\
\text { - Root, cut, drill, and } \\
\text { insert bonding } \\
\text { - Surface grind and } \\
\text { finish }\end{array}$ \\
\hline
\end{tabular}

\section{Additive/Composite Hybrid Structure Manufacturing}

\begin{tabular}{|c|c|c|}
\hline Preprocessing & Processing & Postprocessing \\
\hline $\begin{array}{l}\text { - Mold prep } \\
\text { - Material cutting }\end{array}$ & $\begin{array}{l}\text { - Structural component } \\
\text { manufacturing } \\
\text { - Mold assembly } \\
\text { - Layup of entire } \\
\text { structure }\end{array}$ & $\begin{array}{l}\text { - Washout (optional) } \\
\text { - Root facing } \\
\text { - Surface grind and } \\
\text { finish }\end{array}$ \\
\hline
\end{tabular}

Figure 3. Comparison of the generalized traditional process steps required to manufacture composite tidal turbine blades $[4,13]$ vs. those that are proposed using the additively manufactured internal molds with novel integrated features. 
Manufacturing a tidal turbine blade with a single internal permanent mold may allow for significant innovations to reduce the manufacturing steps shown at the top of Figure 3 and potentially increase the reliability of the structural design. A major advantage of internal molding is that composite plies can be wrapped around the outside of critical design features, such as leading and trailing edges, to create a continuous construction in failure-prone areas, with continuous fibers. Adhesive bond lines are a common place for manufacturing defects, which have regularly contributed to structural failures of wind and tidal turbine blades [16-19]. Structural adhesives are also significantly more expensive per $\mathrm{kg}$ than the low-cost composites they typically bond together [4]. Eliminating these adhesives has generally been hypothesized to lead to significant cost and time savings $[4,20]$.

The same could be achieved with shear webs and box spars. Instead of adhesively bonding premade shear webs during the final blade assembly, an additively manufactured mold could be designed in such a way that it could also serve as a fixture to hold a premade shear web in place to be co-infused with the rest of the composite during the VARIM process. Specifically, printed fixtures to hold mechanical fasteners in place during composite layup have also proven to be beneficial for complex composite component construction [21,22]. This technique could be used for root fasteners and other bolted connections. A well-designed fixture could be printed into the mold to hold the fasteners in place while glass or carbon fabric is wrapped on the top and bottom of the fasteners so they can be co-infused into the structure. More expensive adhesive would be eliminated from the structure, as well as a significant postprocess machining step.

During the layup of the composite for the VARIM process, resin infusion lines are typically placed on top to direct and control the flow of resin through the glass/carbon fabrics. It is often difficult to get good resin flow through thick stacks of fabrics, resulting in porosity and dry areas. Additively manufactured internal molds could allow for the integration of infusion lines directly into the mold for precise control of the resin flow through all layers of fabric. Resin would flow from the mold and into the glass/carbon fabrics, potentially reducing the likelihood of detrimental levels of porosity.

Blades for tidal/ocean current turbines are anticipated to grow to be in excess of $20 \mathrm{~m}$ in length, depending on their site location [1]. Blades of this length can be expensive to transport across land, so there is a desire for on-site manufacturing in shipyards and dry docks to minimize these costs. Segmented mold construction would ensure easy on-site manufacturing or transportation to the manufacturing site. Blade length would not be limited by the size of 3D printers and manufacturing sites. Additively manufactured molds could easily and efficiently be printed in sections and assembled on-site before beginning the composite manufacturing process.

\subsection{Conceptual Design}

We selected a conceptual tidal turbine blade section for this manufacturing demonstration with an additively manufactured internal mold, incorporating all of the novel features and unique innovations described earlier. The blade sections' geometry was based on the blades from the Reference Model 1 (RM1) tidal turbine from the U.S. Department of Energy Reference Model Project [3]. RM1 is a turbine with 9-m rotor blades with NACA $63_{1}-424$ primary airfoil shapes. The blade section was designed to include the root section through to the maximum chord region ( 1.5 m outboard). It should be noted that we simplified the overall blade geometry to some degree for this research. The main goal was to focus on the manufacturing aspects of the blade design, so it is not structurally or hydrodynamically optimized in any way. The demonstration is primarily meant to be representative of a tidal turbine blade.

The additively manufactured mold was to be printed in four separated sections (see Figure 4): a root fixture (a), a root section (b), a transition section (c), and a main foil section (d). The four sections were designed to join together with steel dowel pins for easy and fast construction of the mold. Internal resin tubes were designed to be printed directly 
into the internal cavities of the sections, which were aligned by the dowel pins (see Figure $5 b)$. They were designed so that during the VARIM process, resin could flow from the resin inlet ports in the root section along the length of the blade and then to the high- and low-pressure surfaces into the composite layers.

a.

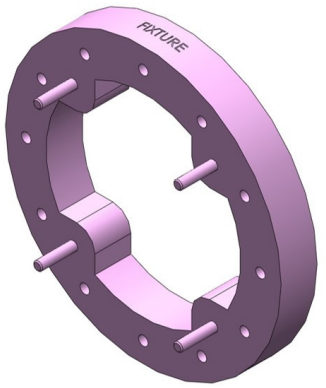

b.

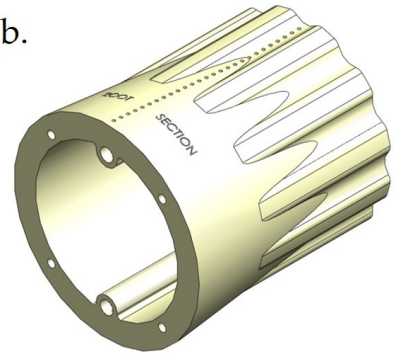

c.

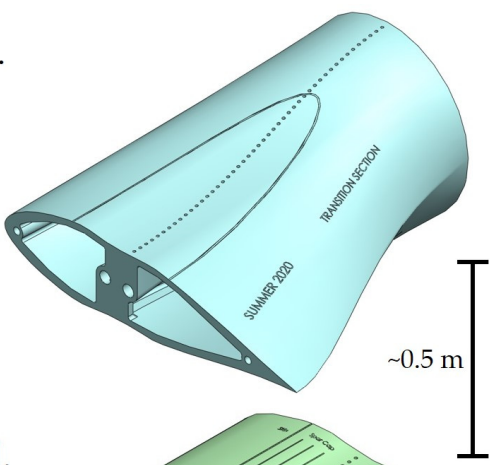

d.

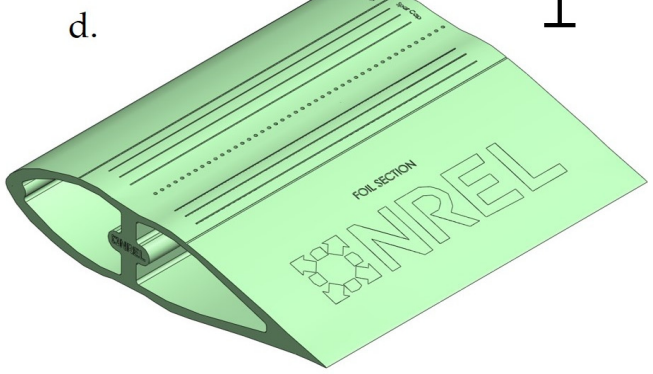

Figure 4. Models of the four mold sections to be printed for the conceptual tidal turbine blade section design where (a) is the sacrificial root fixture, (b) is the root section, (c) is the transition section, and (d) is the main hydrofoil section.

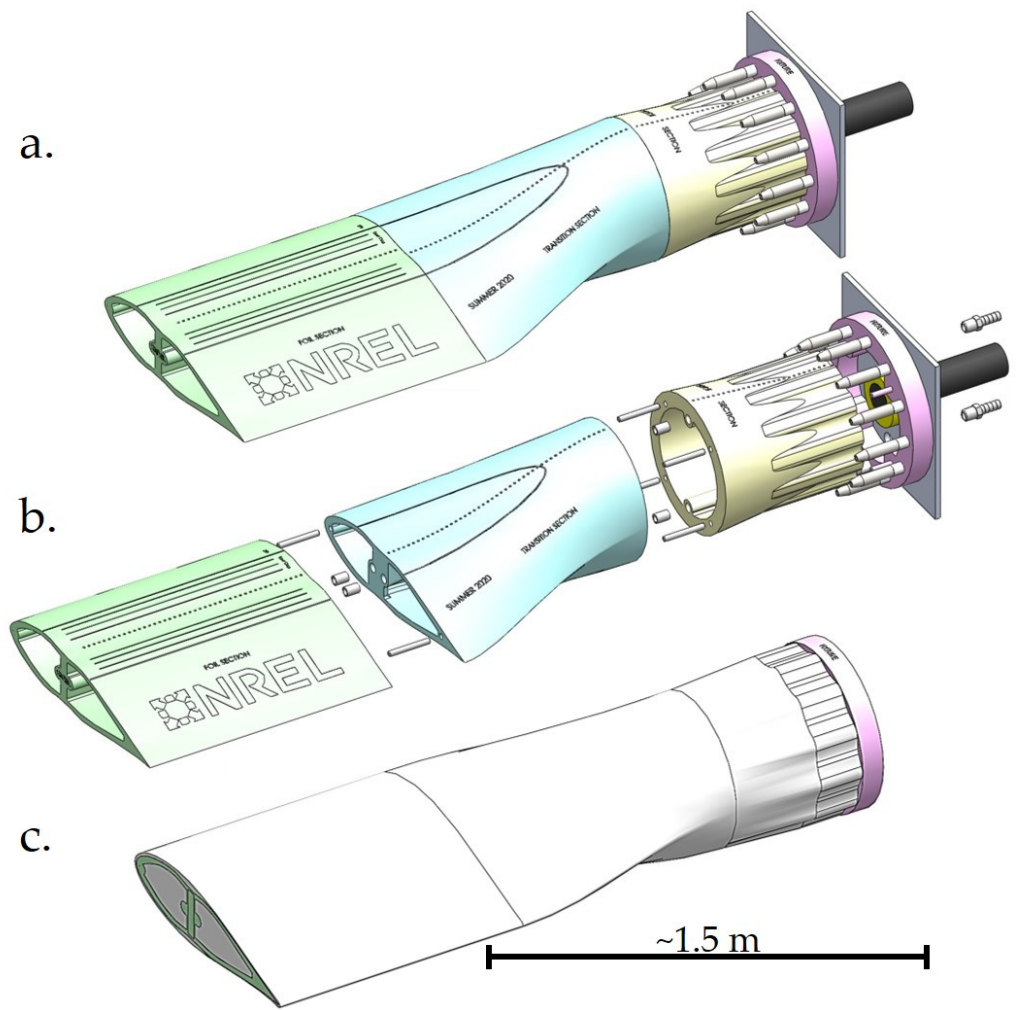

Figure 5. Full assembly drawings of the blade section mold, where (a) is fully assembled, (b) is exploded to show the connections between sections, and (c) includes the composite overlay. 
A shear web fixture was also integrated into the main foil section. It was designed so that a premade web could slide into the fixture, which was then sealed when the mold sections were assembled. The integrated resin tubes were located so resin could flow into the remaining free volume around the shear web before continuing to the surface of the mold, co-infusing the web in place with the resin.

The root section and fixture are particularly unique. The root fixture is a sacrificial feature, functioning as an alignment and fixturing member for the 12 threaded root inserts around the printed root section. The 3D-printed root mold section is designed to account for the glass/carbon fabric and the cylindrical shape of the inserts. To build up the composite root, half of the root plies are laid down before attaching the root inserts, then the remaining root plies can be laid over the top of the inserts. The inserts themselves are tapered at the end to prevent a sudden change in geometry for the overlaying plies. The root fixture is a sacrificial print to be faced off after the composite manufacturing process is complete, leaving a clean, circular root section with the threaded fasteners in situ.

Overall, the outer additively manufactured mold shape and composite layup must be designed concurrently. The outer shape of the mold accounts for the varying thicknesses of the composite layup to preserve the intended hydrodynamic shapes and profiles. The root of the blade has a thick composite buildup that gradually tapers in thickness toward the transition section, hence the reverse taper of the root mold section to be printed. Thicker spar cap sections are also included in the composite design to taper in thickness along the length of the transition and foil sections. Their influence on the mold shape can be observed at the center chord of the main foil section (Figure 4d). The blade is also designed to have a thin, continuous skin layer covering the entire outer surface of the blade section.

Finally, a thick, reusable, machined steel plate was mounted to the root fixture, so the fully assembled mold could be secured to a stand. This allowed the mold to be easily maneuvered and rotated to expedite the composite layup and infusion process.

\section{Manufacturing}

To properly demonstrate the potential of internal molds for hybrid composite marine energy structures, the conceptual design described above was used to manufacture a reduced-scale model. The purpose of the model was not only to display the capabilities but also to clearly identify specific features that were particularly useful, as well as those that were not. It also helped us recognize key areas for continued research to allow this design and manufacturing approach to be viable for future iterations. The blade section was reduced to a blade approximately $0.75 \mathrm{~m}$ in length with a $0.3 \mathrm{~m}$ maximum chord length. Manufacturing was conducted at the National Renewable Energy Laboratory's Composites Manufacturing Education and Technology (CoMET) facility.

\subsection{Additively Manufactured Mold Preparation}

The four mold sections were printed from acrylonitrile butadiene styrene (ABS) plastic with a Stratasys Fortus 400MC FDM printer. The sections were printed with a double-dense sparse in-fill to reduce material usage and printing times and ensure geometric integrity when vacuum pressure was applied for the VARIM process. Before assembly, each mold section was sealed to ensure that vacuum integrity could be maintained throughout the resin infusion process. This was done following Stratasys's recommendations for sealing additively manufactured composite molds [12]. The internal and external surfaces were sanded, coated with a fast-curing wet-layup epoxy from West Systems, and sanded again (see Figure 6). 


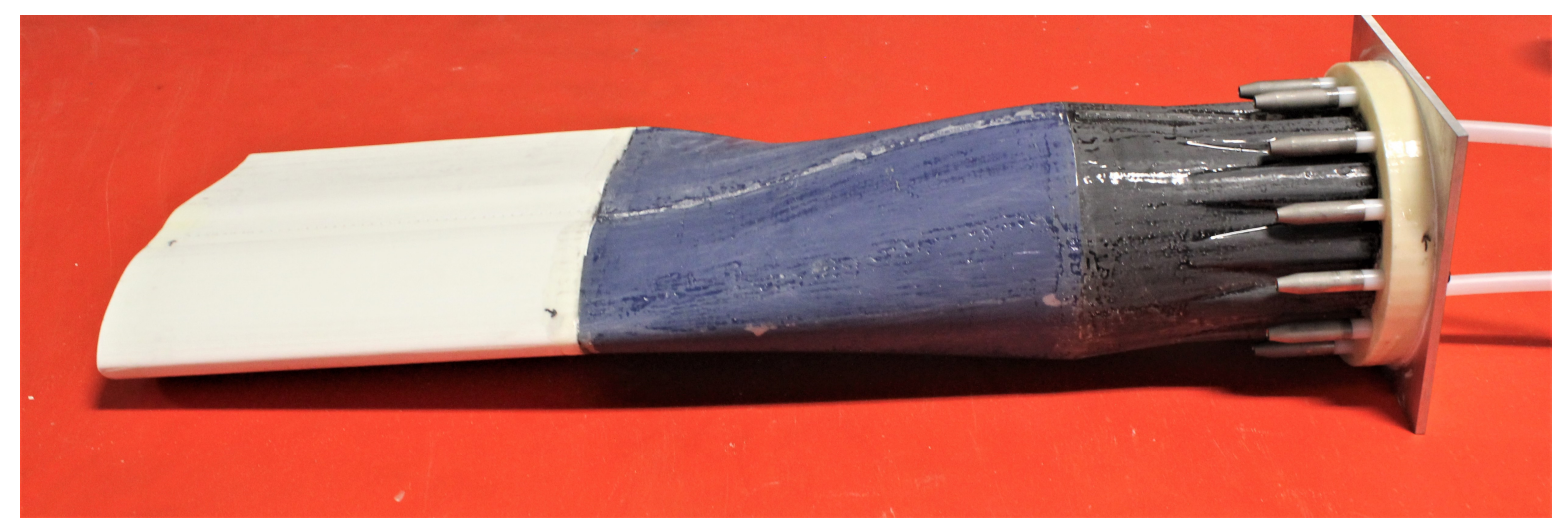

Figure 6. The 3D-printed mold sections after being sanded, sealed with epoxy, and fully assembled, ready for the composite manufacturing process. The root inserts were bolted in place for display purposes.

After sealing, the mold sections were joined and bonded using the prescribed dowel pins, nylon bushings, and structural adhesive, although other techniques such as thermal welding could have achieved the same effect without the expensive adhesive $[12,20]$. The premade shear web was also installed before bonding the main foil and transition section together, so it was secured in place for the VARIM process. The shear web was a flat sandwich panel manufactured from epoxy-resin-infused triaxial fiberglass and a structural foam core. Finally, the mold was vacuum-bagged, and a leak test was performed to confirm adequate vacuum integrity for the VARIM process. Figure 6 shows the final assembled additively manufactured mold ready for the composite layup and infusion process.

\subsection{Composite Layup and Infusion}

As mentioned in Section 2.2, we designed the composite layup concurrently with the additively manufactured mold to achieve the desired outer hydrodynamic profiles. A triaxial fiberglass fabric with an average ply thickness of $0.9 \mathrm{~mm}$ was used for all areas of the blade section. The root was designed to incorporate 14 plies tapering in length over the root section of the mold. The spar caps were designed to be four plies thick and tapered in both length and width toward the main foil section of the mold. Finally, a single skin ply was to be wrapped over the full length and chord of the mold. A structural flow fiberglass media was used as the first ply to encourage resin flow across the entire mold. As previously stated, this was not intended to be an optimized structural design, but rather a representative design for manufacturing purposes.

Figure 7 shows the layup process. First, the structural flow media was applied to the mold and held in place with spray adhesive. The first half of the root plies could then be applied, followed by all 12 of the root inserts (see Figure 7a). The remaining 7 root plies were then placed over the top of the inserts (see Figure $7 \mathrm{~b}$ ). The high-pressure and low-pressure spar cap plies were then installed (see Figure 7c), followed by the final skin ply, which was wrapped tightly around the leading and trailing edges to ensure tight contours in those critical areas (see Figure 7d). The blade section was then vacuum-bagged with vacuum lines installed along the leading and trailing edges to ensure resin flow from the center of the mold over the entire surface and to control it during the infusion process. 


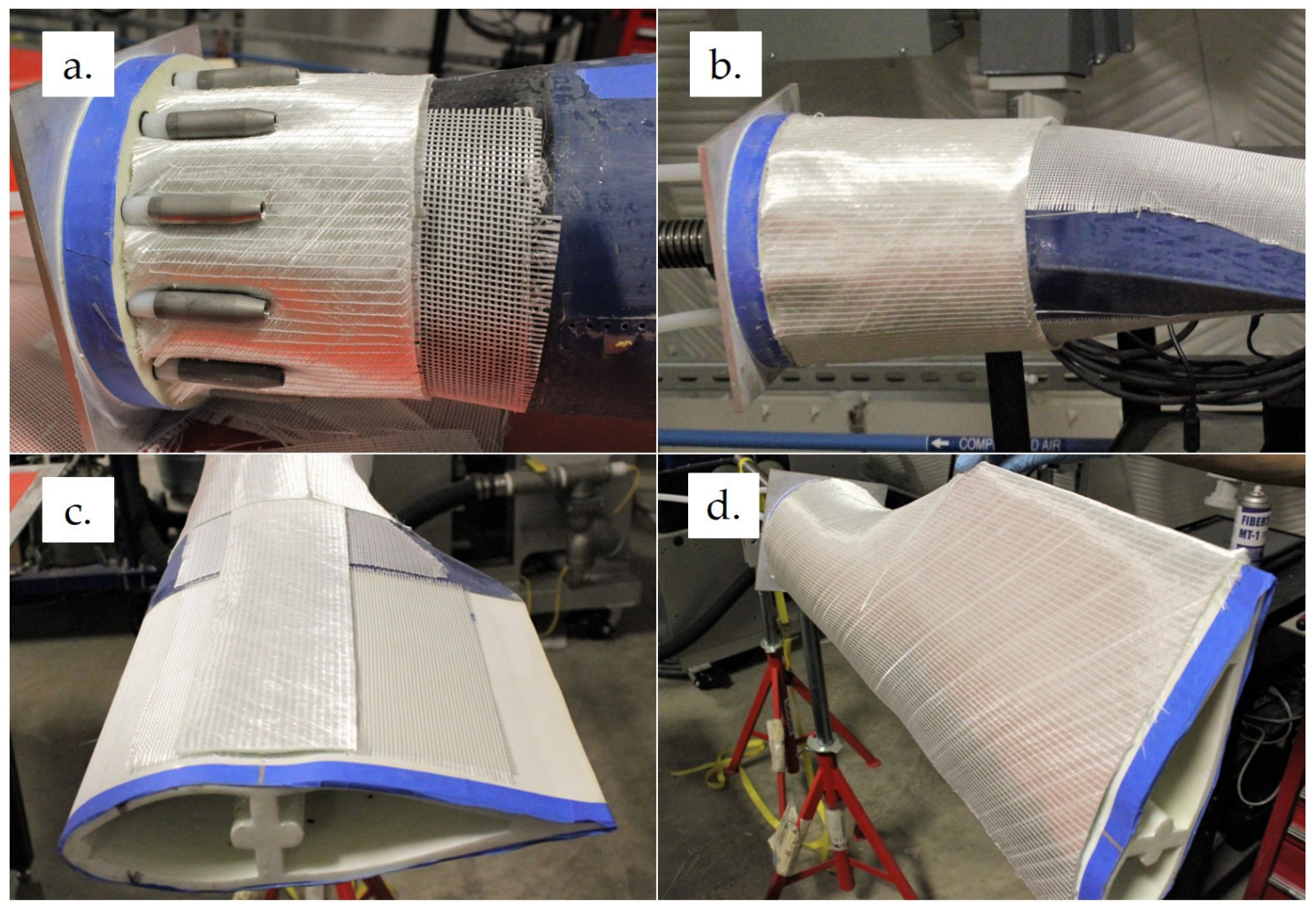

Figure 7. Showing the composite layup process with (a) the first half of the root plies and root inserts installed, (b) the second half of the root plies, (c) the spar caps, and (d) the final skin ply.

For the resin infusion process, we used Hexion's Epikote RIMR135/Epikure RIMH1366 two-part epoxy resin system, which is commonly used in the manufacturing of wind turbine blades [23]. Figure 8 shows the VARIM process. The transition section wet out first, followed by the thicker root section. The main foil section was last to fully saturate because the epoxy resin had to flow around the shear web before reaching the main surfaces. Overall, the entire blade section became fully saturated with epoxy as intended.

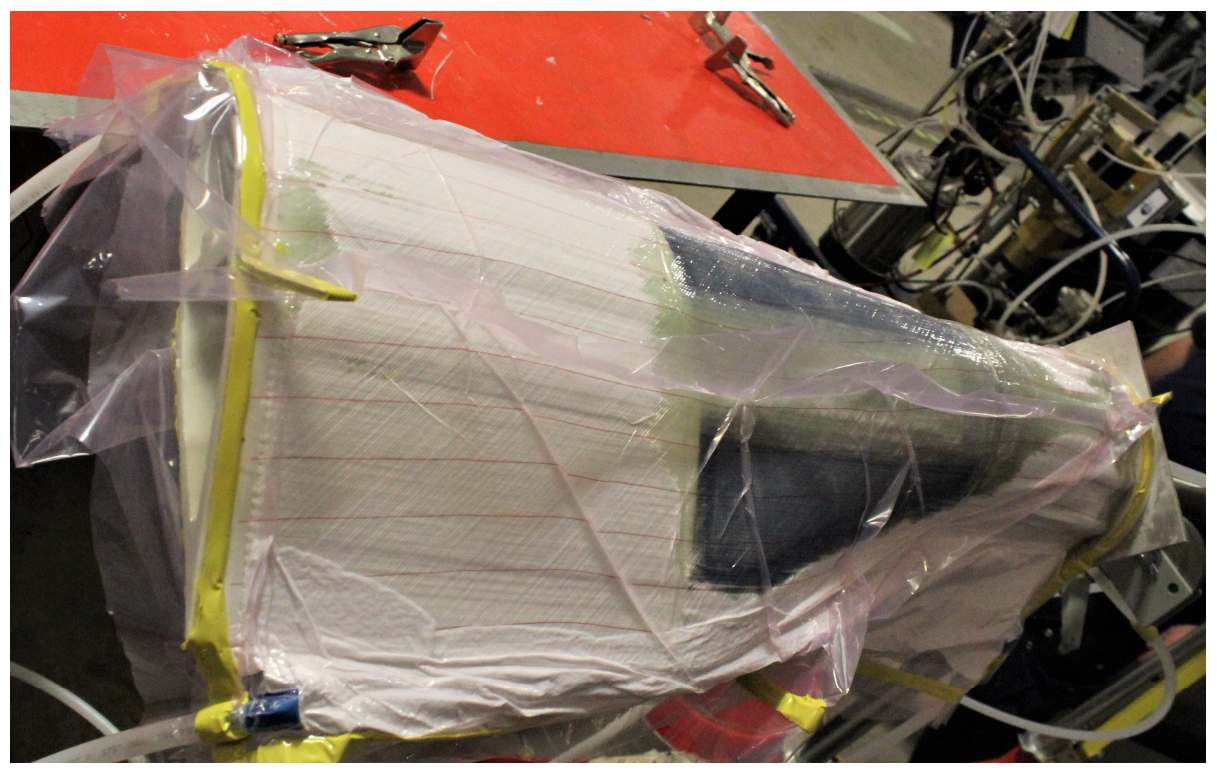

Figure 8. Photo taken mid-infusion, showing the epoxy resin saturating the fiberglass around the transition section and beginning to flow through the root and main foil sections. 


\subsection{Final Finishing}

Once cured, the vacuum bag and other infusion materials were removed from the blade section. The root was then prepared by removing the fasteners and slicing off the sacrificial root fixture portion of the mold. The surface was then faced to be flush with the threaded root inserts. Figure 8 shows the draping of the triaxial fiberglass fabric around the cylindrical insert and the remaining root section of the mold in place.

The end of the main foil section was also sliced to better observe the resin flow through the fixture surrounding the premade shear web (see Figure 9). The epoxy resin flowed well around the web, with no visible dry spots around the structural foam. This crosssection also shows that the resin flowed into portions of the reduced density cavities in the 3D-printed mold.

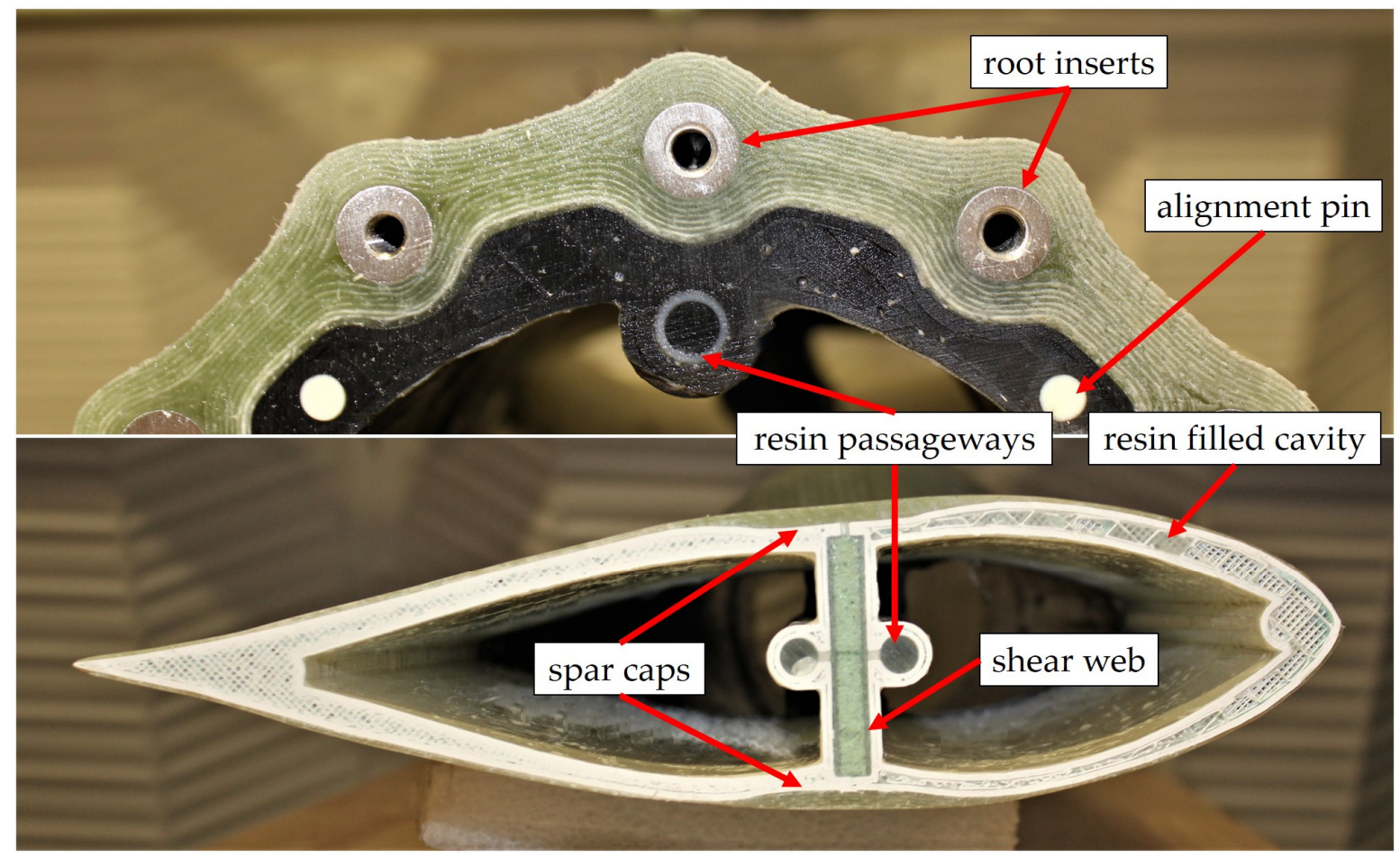

Figure 9. The final faced surface of the root end of the blade section (top) showing the draping of the fiberglass plies over and under the root inserts, and the main foil section (bottom) to show the profiles of the final spar caps and shear web. Epoxy resin in the sparsely filled internal cavities of the 3D print can also be observed.

The surface was ground and sanded smooth using an orbital sander and gradually increasing sandpaper grits, as is standard practice, until the surface was free of visible waves and discontinuities. Figure 10 shows the final, finished, reduced-scale tidal turbine blade section. Overall, the additively manufactured internal mold approach to manufacturing the blade section required significantly less time and effort than applying conventional mold manufacturing techniques to produce two half-blade section molds and then manufacturing a blade section from them. This is in comparison with the extensive experience gained through conventional manufacturing of tidal and wind turbine blades previously in the CoMET facility $[13,14]$, as well as with a variety of industry partners. The facing of the blade root was quick and simple, and there were absolutely no secondary bonding processes required. Surface grinding and finishing was more time-consuming than typical but was more than made up for by the reduction and elimination of other process steps. 


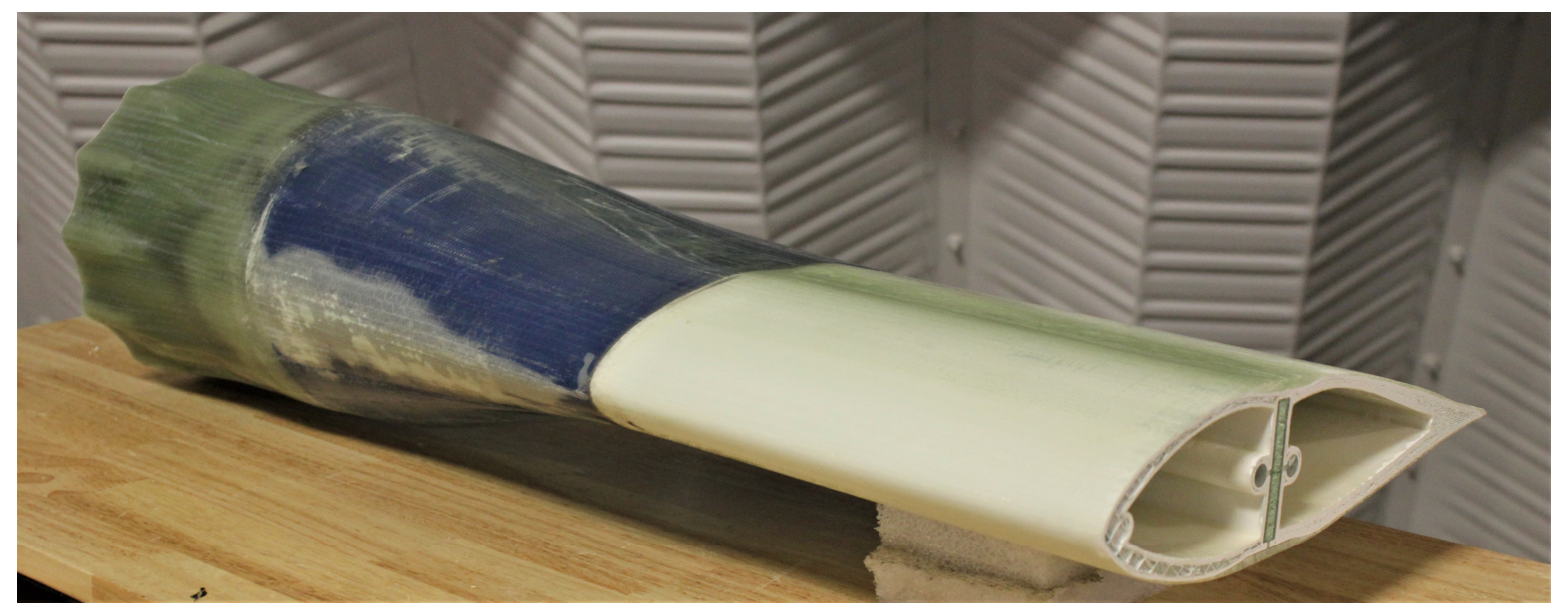

Figure 10. The final finished blade section with visible out-of-plane waves stemming from the root inserts and the delamination along the leading edge of the transition region.

\section{Discussion}

The goal of this research was to identify the manufacturing potential for using additive manufacturing for internal molding to produce hybrid composite structures for marine energy systems. Through this research, we demonstrated the many potential benefits and key features that permanent additively manufactured tooling could allow for. As a proof of concept, we conceptually designed and manufactured a reduced-scale tidal turbine blade section, which integrated a number of novel features made possible through additive manufacturing. Gaining hands-on experience allowed for a much greater understanding of how to properly implement the technology in a manufacturing environment and helped identify important requirements for future research. This section provides a discussion of the key findings from the design and manufacturing process.

\subsection{Mold Design}

The process of designing the additively manufactured mold itself did not have a significant influence on the design process from a manufacturing perspective. Once the composite ply layout had been designed, the composite thicknesses were subtracted from the intended net external geometry of the blade section, leaving the final outer surface geometry of the mold to be printed. This required some intuition during the CAD drawing process but could be much more streamlined with the use of specialized composite design and ply draping software. The implementation of the integrated shear web, resin infusion lines, root fasteners, and mold segmentation were also straightforward in the design for manufacturing approach, although ensuring that the complex internal structures of the mold could be perfectly sealed required forethought. Nonetheless, there is plenty of room for further optimization of this design in the future, especially from a structural integrity perspective.

Another area for extensive optimization in the additively manufactured mold design is the in-fill and wall thickness parameters for the internal cavities of the 3D print. We chose a sparse, double-dense in-fill to reduce material usage and print times, and also to minimize distortion of the mold as a result of vacuum pressure (see Figure 9). In future designs, this aspect must be carefully considered, especially if the mold is intended to remain as a load-bearing component in the full-scale hybrid additively manufactured/composite structure. Segmented optimization or even full topology optimization of mold designs could give way to highly efficient, advanced hybrid composite structures. In addition, print and lead times, as well as material costs, could be significantly reduced for prototype and large-scale-manufacturing marine energy structures. This will be a specific focus for future research. 
Material selection for the blade section design and manufacturing was relatively conservative. The mold was printed with ABS plastic because of its low cost, and the composite was fiberglass infused with a room-temperature-cure epoxy. We chose this specific epoxy because of its low exotherm temperatures during curing, so it was compatible with the ABS mold. ABS has a relatively low heat deformation temperature and may have permanently deformed if a higher temperature cure resin was used. To 3D-print a mold also intended to be a structural element, chopped fiber-filled or even continuous fiber thermoplastic filaments would be a better choice, because of their higher stiffnesses, strengths, and heat deformation temperatures. Their lower coefficients of thermal expansion would also be beneficial. In turn, this would allow for a much broader selection of resin systems for the VARIM process. Novel, infusible thermoplastic resin systems are showing great promise for renewable composite applications [13]. They exhibit similar mechanical properties to epoxy resin systems, with the added benefit of being recycled more easily [24]. The combination of a thermoplastic, 3D-printed hybrid mold with a thermoplastic composite would allow for fully recyclable structures at the end of their service life [25]. This would be an important economic and sustainable benefit for the marine energy industry.

\subsection{Manufacturing}

Once printed, the mold sections were sanded and then sealed with a fast-curing, wet layup epoxy resin system. This was by far the most time-consuming step of the manufacturing process, mainly because of the complex internal shapes of the mold. The inside of the resin infusion passageways and the shear web fixture could not be sealed. This was sufficient to provide a good vacuum seal for the VARIM process but did lead to other issues. The resin was drawn into the internal cavities of the 3D prints (see Figure 9), leading to a significant increase in the resin required for the infusion. Based on estimates from an assumed fiber mass fraction for the VARIM process, the total mass of the fiberglass, and the volumes of the internal mold cavities, the part absorbed almost three times as much epoxy as was calculated to be required. Because of this, better sealing methods are required for 3D-printed molds with hard-to-reach, complex geometries and design features. Techniques such as vapor smoothing with acetone [26] may be very useful for this type of application, but will require stricter controls when applied on a larger scale. More research is required in this area.

Hands-on manufacturing of the conceptual design provided a true understanding of which design features were particularly beneficial for the manufacturing process. The segmented mold construction was simple to implement and would be beneficial for transportation or on-site manufacturing of large components. In fact, it made sealing the harder-to-reach areas of the mold easier while it was still segmented. Integrating the root fasteners also worked as intended, as well as the integrated shear web fixture. The premade shear web was easily inserted and sealed into the mold for infusion. On a larger scale, more considerations would need to be made for the thickness taper and hydrodynamic twist of the tidal turbine blade. Both the integrated root fasteners and shear web features proved to be incredibly useful, removed time-consuming steps from the manufacturing process, and eliminated the need for costly, defect-prone adhesive bonding steps.

The only design features that proved to be a hindrance were the integrated resin passageways. As described earlier, it was not possible to seal the inside of them, which led to excessive resin uptake. In this case, they were not worth the additional design and manufacturing effort, although their presence was useful for providing resin flow around the shear web. Despite the disadvantages, this research has demonstrated that it is possible to implement integrated resin passageways as a 3D-printed design feature. They may still become useful for other more complex composite geometries in the future, wherein accurate resin flow is critical.

Final finishing of the blade section was a critical step in the manufacturing process. It was already understood that this was where the novel internal molding process would be at a disadvantage to traditional female molding techniques. Overall, the finishing process 
was not much more time-consuming than is typically required for a tidal turbine blade based on past manufacturing experience in the CoMET, but other issues were uncovered. The spar caps needed a substantial amount of material removed to meet the designed hydrodynamic surface geometry. This would be detrimental to the integrity of a full-scale blade structure. Great care also needed to be taken around the trailing edge region to avoid grinding through the skin plies to the mold surface. In light of these issues, the grinding and sanding process could be accounted for in the design process. Low-cost "sacrificial" plies, such as chopped-strand mats could be included in the composite layup design, so that the critical skin and spar cap plies would not get damaged by the finishing process.

Figure 10 shows some visible out-of-plane waves in the composite around the root of the blade section that were not removed during the final finishing process. Although they were far away from the main hydrofoil portion of the blade section, manufacturing defects like these can become damage initiation points under loading of the structure [27]. They were caused by the sharp changes in geometry of the mold surface and root inserts, resulting in the triaxial fabric wrinkling. Further design of the root insert geometry or different glass fabric selection would help alleviate these wrinkles. The triaxial fabric used was relatively stiff and not easily draped over complex contours. The drapability of fabrics should be carefully considered for future designs when sharp contours are present. The scale of the blade section may have contributed to this issue. It is expected that the waves would be much less prominent on a larger-scale component.

The final defect observed on the manufactured blade section was a large delamination along the leading edge of the transition region (see Figure 10). This was caused by the removal of the vacuum bag from the cured part. Ultimately, the 3D-printed mold will be intended to be a load-bearing component of the composite structure, so delaminations such as these would be unacceptable, and good adhesion between the 3D print and the composite overlay is critical. The mold surface was prepared in a comparable way to adhesive bonding surfaces but, clearly, that was insufficient. More research is required to develop surface preparation practices for bonding these dissimilar materials. It appears there is currently very little information available for such requirements.

To summarize, the main goal of this research was to investigate the potential for additive manufacturing to be applied to the creation of marine energy composite structures through internal molding to produce advanced hybrid structures. Our investigation has indicated that additive manufacturing of internal composite molds can allow for a unique design approach which can have the potential to reduce costs and lead times. Future research will focus on a fully optimized structural design, which will then allow for proper in-depth techno-economic analyses for comparison with conventional manufacturing techniques. Ultimately, additive manufacturing of internal hybrid structural molds could help pave the way for a new generation of low-cost, highly reliable, recyclable, and advanced marine energy composite structures.

Author Contributions: Conceptualization, P.M. and D.M.; methodology, P.M., J.D., and R.B.; design, P.M., J.D., D.M., S.H., and R.B.; manufacturing and validation, P.M., J.D., and R.B.; writing-original draft preparation, P.M.; writing — review and editing, J.D., D.M., S.H., and R.B.; funding acquisition, P.M., D.M., and S.H. All authors have read and agreed to the published version of the manuscript.

Funding: This work was authored by the National Renewable Energy Laboratory, operated by the Alliance for Sustainable Energy, LLC, for the U.S. Department of Energy (DOE) under Contract No. DE-AC36-08GO28308. Funding provided by the U.S. Department of Energy Office of Energy Efficiency and Renewable Energy Water Power Technologies Office. The views expressed in the article do not necessarily represent the views of the DOE or the U.S. Government. The U.S. Government retains and the publisher, by accepting the article for publication, acknowledges that the U.S. Government retains a nonexclusive, paid-up, irrevocable, worldwide license to publish or reproduce the published form of this work, or allow others to do so, for U.S. Government purposes.

Institutional Review Board Statement: Not applicable.

Informed Consent Statement: Not applicable. 
Data Availability Statement: The data presented in this study are available on request from the corresponding author.

Acknowledgments: The authors would like to thank all the engineers and technicians who provided their knowledge and expertise for this project, particularly David Barnes and Casey Nichols. The authors would also like to thank Bernadette Hernandez-Sanchez from Sandia National Laboratories and Lauren Ruedy from the U.S. Department of Energy's Water Power Technologies Office for their valued input throughout the project. Finally, we would like to thank Paul Ubrich from Hexion Inc. for supplying the epoxy resin system used in this study.

Conflicts of Interest: The authors declare no conflict of interest.

\section{References}

1. Neary, V.S.; Previsic, M.; Jepson, R.A.; Lawson, M.J.; Yu, Y.H.; Copping, A.E.; Fontaine, A.A.; Hallet, K.C.; Murray, D.K. Methodology for Design and Economic Analysis of Marine Energy Conversion (MEC) Technologies; Sandia National Larboratories: Albuquerque, NM, USA, 2014.

2. Nunemaker, J.D.; Voth, M.M.; Miller, D.A.; Samborsky, D.D.; Murdy, P.; Cairns, D.S. Effects of moisture absorption on damage progression and strength of unidirectional and cross-ply fiberglass-epoxy laminates. Wind Energy Sci. 2018, 3, 427-438. [CrossRef]

3. Bir, G.; Lawson, M.J.; Li, Y. Structural design of a horizontal-axis tidal current turbine composite blade. In Proceedings of the ASME 30th International Conference on Ocean, Offshore and Arctic Engineering, Rotterdam, The Netherlands, 19-24 June 2011. [CrossRef]

4. Murray, R.E.; Jenne, S.; Snowberg, D.; Berry, D.; Cousins, D.S. Techno-economic analysis of a megawatt-scale thermoplastic resin wind turbine blade. Renew. Energy 2019, 131, 111-119. [CrossRef]

5. Post, B.; Richardson, B.; Lloyd, P.; Love, L.; Nolet, S.; Hannan, J. Additive Manufacturing of Wind Turbine Molds; Oak Ridge National Laboratory: Oak Ridge, TN, USA, 2017. [CrossRef]

6. Post, B.K.; Chesser, P.C.; Roschli, A.C.; Love, L.J.; Gaul, K.T. Large-Scale Additive Manufacturing for Low Cost Small-Scale Wind Turbine Manufacturing; Oak Ridge National Laboratory: Oak Ridge, TN, USA, 2018. [CrossRef]

7. Post, B.K.; Richardson, B.; Lind, R.; Love, L.J.; Lloyd, P.; Kunc, V.; Rhyne, B.J.; Roschli, A.; Hannan, J.; Nolet, S.; et al. Big Area Additive Manufacturing Application in Wind Turbine Molds. In Proceedings of the 28th Annual International Solid Freeform Fabrication Symposium-An Additive Manufacturing Conference, Austin, TX, USA, 7-9 August 2017.

8. Bassett, K.; Carriveau, R.; Ting, D.S.K. 3D printed wind turbines part 1: Design considerations and rapid manufacture potential. Sustain. Energy Technol. Assess. 2015, 11, 186-193. [CrossRef]

9. Li, H.; Taylor, G.; Bheemreddy, V.; Iyibilgin, O.; Leu, M.; Chandrashekhara, K. Modeling and characterization of fused deposition modeling tooling for vacuum assisted resin transfer molding process. Addit. Manuf. 2015, 7, 64-72. [CrossRef]

10. Wang, X.; Jiang, M.; Zhou, Z.; Gou, J.; Hui, D. 3D printing of polymer matrix composites: A review and prospective. Compos. Part B Eng. 2017, 110, 442-458. [CrossRef]

11. van der Kilft, F.; Koga, Y.; Todoroki, A.; Ueda, M.; Hirano, Y.; Matsuzaki, R. 3D Printing of Continuous Carbon Fibre Reinforced Thermo-Plastic (CFRTP) Tensile Test Specimens. Open J. Compos. Mater. 2016, 6, 18-27. [CrossRef]

12. Stratasys. FDM for Composite Tooling 2.0: Design Guide; Stratasys, Ltd.: Eden Prairie, MN, USA, 2017.

13. Murray, R.E.; Snowberg, D.; Berry, D.; Beach, R.; Rooney, S.; Swan, D. Manufacturing a 9-meter thermoplastic composite wind turbine blade. In Proceedings of the American Society for Composites 32nd Technical Conference, West Lafayette, IN, USA, 23-25 October 2017. [CrossRef]

14. Murray, R.E.; Beach, R.; Barnes, D.; Snowberg, D.; Berry, D.; Rooney, S.; Jenks, M.; Gage, B.; Boro, T.; Wallen, S.; et al. Structural validation of a thermoplastic composite wind turbine blade with comparison to a thermoset composite blade. Renew. Energy 2021, 164, 1100-1107. [CrossRef]

15. Camanho, P.P.; Matthews, F.L. Stress analysis and strength prediction of mechanically fastened joints in FRP: A review. Compos. Part A Appl. Sci. Manuf. 1997, 28, 529-547. [CrossRef]

16. Al-Khudairi, O.; Hadavinia, H.; Little, C.; Gillmore, G.; Greaves, P.; Dyer, K. Full-Scale Fatigue Testing of a Wind Turbine Blade in Flapwise Direction and Examining the Effect of Crack Propagation on the Blade Performance. Materials 2017, 10, 1152. [CrossRef] [PubMed]

17. Chen, X.; Berring, P.; Madsen, S.H.; Branner, K.; Semenov, S. Understanding progressive failure mechanisms of a wind turbine blade trailing edge section through subcomponent tests and nonlinear FE analysis. Compos. Struct. 2019, 214, 422-438. [CrossRef]

18. Jensen, F.M.; Falzon, B.G.; Ankersen, J.; Stang, H. Structural testing and numerical simulation of a $34 \mathrm{~m}$ composite wind turbine blade. Compos. Struct. 2006, 76, 52-61. [CrossRef]

19. Lahuerta, F.; Koorn, N.; Smissaert, D. Wind turbine blade trailing edge failure assessment with sub-component test on static and fatigue load conditions. Compos. Struct. 2018, 204, 755-766. [CrossRef]

20. Murray, R.E.; Roadman, J.; Beach, R. Fusion joining of thermoplastic composite wind turbine blades: Lap-shear bond characterization. Renew. Energy 2019, 140, 501-512. [CrossRef]

21. Türk, D.-A.; Kussmaul, R.; Zogg, M.; Klahn, C.; Leutenecker-Twelsiek, B.; Meboldt, M. Composites Part Production with Additive Manufacturing Technologies. Procedia CIRP 2017, 66, 306-311. [CrossRef] 
22. Türk, D.-A.; Triebe, L.; Meboldt, M. Combining Additive Manufacturing with Advanced Composites for Highly Integrated Robotic Structures. Procedia CIRP 2016, 50, 402-407. [CrossRef]

23. Murdy, P. Combining Acoustic Emission and Guided Ultrasonic Waves for Global Property Prediction and Structural Health Monitoring of Glass Fiber Composites. Ph.D. Thesis, Montana State University, Bozeman, MT, USA, 2018.

24. Cousins, D.S.; Suzuki, Y.; Murray, R.E.; Samaniuk, J.R. Recycling glass fiber thermoplastic composites from wind turbine blades. J. Clean. Prod. 2019, 209, 1252-1263. [CrossRef]

25. Rybnicek, J.; Lach, R.; Lapcikova, M.; Steidl, J.; Krulis, Z.; Grellmann, W.; Slouf, M. Increasing recyclability of PC, ABS and PMMA: Morphology and fracture behavior of binary and ternary blends. J. Appl. Polym. Sci. 2008, 109, 3210-3223. [CrossRef]

26. Singh, R.; Singh, S.; Singh, I.P.; Fabbrocino, F.; Fraternali, F. Investigation for surface finish improvement of FDM parts by vapor smoothing process. Compos. Part B Eng. 2017, 111, 228-234. [CrossRef]

27. Murdy, P.; Hughes, S. Investigating Core Gaps and the Development of Subcomponent Validation Methods for Wind Turbine Blades: Preprint. In Proceedings of the AIAA SciTech Forum, Orlando, FL, USA, 6-10 January 2020. [CrossRef] 